\title{
Outpatient Diabetic Care in a Public Central Hospital: Patient Characteristics, Therapeutic Regimens and Results
}

\author{
Joao Martin Martins ${ }^{\mathrm{a}, \mathrm{b}}$, Sonia do Vale ${ }^{\mathrm{a}}$, Ana Filipa Martins ${ }^{\mathrm{a}}$, \\ Ana Raquel Gomes ${ }^{\text {a }}$ Lagoa Vicente ${ }^{a}$, Jorge Caldeira ${ }^{a}$
}

\begin{abstract}
Background: Report of patient characteristics, treatment and results of diabetic patients assisted at a public tertiary hospital.

Patients and Methods: Standardized clinical and analytical data regarding patients assisted during 2 years.

Results: Nine hundred and seventy-one visits and 271 patients were studied. Patients with type 1 (DM1) (15\%), type 2 treated with insulin (DM2-IT) (23\%) and type 2 treated with oral agents (DM2NIT) $(56 \%)$ were included. On referral, long-standing disease (11 \pm 9 years) was present with poor metabolic control (glycated hemoglobin, HbA1c $8.4 \pm 2.0 \%$ ). Microvascular disease (33-40\%), high blood pressure (HBP) (56\%) and dyslipidemia (61\%) were common. Intensive treatment was used in less than half of the patients. Most of DM2 patients were under medication for HBP and were using anti-platelet agents (76\%) but less than half (46\%) were using lipid-lowering drugs. Despite frequent medical visits, metabolic control remained poor, HbA1c $8.0 \pm 1.9 \%$. In almost half of DM2 patients, systolic blood pressure $(45 \%)$, serum cholesterol $(36 \%)$, serum triglycerides (42\%) and HDLc (37\%) remain higher or lower than recommended.
\end{abstract}

Conclusions: Two fundamental vectors seem to underlie the clinical evolution: aging and $\beta$-cell function. DM2-IT represents a group of specially difficult patients. Intensive medical assistance of diabetic patients is still far from routine even in tertiary hospitals.

Keywords: Diabetic patients; Metabolic control; Blood pressure; Dyslipidemia

\footnotetext{
Manuscript accepted for publication February 10, 2014

${ }^{a}$ Endocrine, Diabetes and Metabolic Department, Hospital de Santa Maria, and Lisbon Medical School, Lisbon, Portugal

${ }^{\mathrm{b}}$ Corresponding author: Joao Martin Martins, Servico de Endocrinologia, Diabetes e Metabolismo, Hospital de Santa Maria, Piso 6, Av. Professor Egas Moniz, 1649-028, Lisbon, Portugal.

Email: jmartinmartins@sapo.pt
}

doi: http://dx.doi.org/10.14740/jem205w

\section{Introduction}

The increasing prevalence of diabetes mellitus in modern Western-like societies is a major public health problem, with significant economic and social consequences [1-3].

At a more basic level, the medical assistance of diabetic patients is a challenging and time-consuming task. This is so, because diabetes mellitus is a chronic life-long condition that requires the active participation of the patient, and imposes major behavioral changes with significant personal, intra-familial, job-related and financial consequences. Furthermore, the medical assistance must consider a multifactorial approach, since besides the central objective of a good metabolic control, acute decompensations must be avoided even during unusual circumstances and chronic complications must be actively sought and treated [4]. It is therefore not surprising that health care costs more than double after the diagnosis of diabetes is made, although it may be more unexpected that per capita costs are greater in type 2 diabetics and that hospitalizations account for more than $70 \%$ of these costs [5]. In the last 10 years, prescription costs for diabetics increased by more than $50 \%$ [6].

In the last two decades, seminal clinical studies have addressed several pertinent issues. These include the objective evaluation of intensive medical treatment [7-11], the possibility of preventing and/or delaying diabetes mellitus [12$20]$ and the possibility of preventing cardiovascular disease [9, 21-31]. These pivotal studies have redefined the ambiance of medical practice. It remains however to be seen how the results of those studies have been incorporated in the real conditions of medical practice. Different settings of course impose specific constraints. We think therefore useful to objectively report patient characteristics and results of medical treatment in one center. Comparing different experiences may provide useful insights and keys to improve the medical assistance of diabetic patients [32-34].

Portugal is a rather small and homogeneous country (area $89,000 \mathrm{~km}^{2}$; population 10,000,000 inhabitants) at the western frontier of Europe. Following a general trend, the older population ( $>65$ years) now represents $15 \%$ of the total. The gross domestic product is about $2 / 3$ of the mean of 
Table 1. Patient Clinical Characteristics

\begin{tabular}{lc}
\hline Gender $(\mathrm{M} / \mathrm{F})(\%)$ & $48 / 52$ \\
Age $($ years $)$ & $55 \pm 16(9-85)$ \\
Years since diagnosis & $11 \pm 9(1-41)$ \\
BMI $\left(\mathrm{kg} / \mathrm{m}^{2}\right)$ & $28.0 \pm 5.7(17.1-51.6)$ \\
Underweight $\left(\mathrm{BMI}<18 \mathrm{~kg} / \mathrm{m}^{2}\right)(\%)$ & 2 \\
Overweight $\left(25<\mathrm{BMI}<30 \mathrm{~kg} / \mathrm{m}^{2}\right)(\%)$ & 32 \\
Obesity $\left(\mathrm{BMI}>30 \mathrm{~kg} / \mathrm{m}^{2}\right)(\%)$ & 30 \\
& \\
Retinopathy $(\%)$ & 35 \\
Cataracts $(\%)$ & 38 \\
Nephropathy $(\%)$ & 40 \\
Cystopathy $(\%)$ & 10 \\
Gastroenteropathy $(\%)$ & 3 \\
Peripheral neuropathy $(\%)$ & 33 \\
Diabetic foot $(\%)$ & 3 \\
High blood pressure $(\%)$ & 36 \\
Dyslipidemia $(\%)$ & 36 \\
Ischemic heart disease $(\%)$ & 3 \\
Cerebrovascular disease $(\%)$ & 3 \\
Peripheral vascular disease $(\%)$ & 3 \\
\hline
\end{tabular}

Results are presented as $\%$, or as the mean \pm standard deviation and between parenthesis the range.

the European Union, and depends mainly on the tertiary sector. Despite the almost universal access to basic commodities, there is marked social inequality, poverty affects $18 \%$ of the population and $15 \%$ of the population is unable to read, while $57 \%$ have only the basic 6 -year education program [35-38].

Health indicators in Portugal are similar to those of other European countries, with a life expectancy at birth of 72 and 79 years for males and females, a death rate of $9 \%$ and the infant death rate of 5\%. For a population of 10,000,000 inhabitants, there are annually 33,000,000 outpatient visits, $10,000,000$ emergency visits and 1,000,000 hospital admissions. The number of doctors, slightly above 30,000, and nurses almost 40,000 is considered adequate or almost so according to international recommendations. Public health spending is around $8 \%$ of the gross domestic product, although $40 \%$ of health costs are paid directly by the patient $[38,39]$. Like in other European countries, media evaluation of the Public Health System is generally negative, contrasting with patient evaluation [40]. A recent report of the World Health Organization ranks Portugal 12th worldwide regarding medical assistance [41].

The prevalence of diabetes mellitus in Portugal is estimated between 4 and $6 \%(\approx 500,000$ patients $)$. From this around $5-10 \%$ are type 1 diabetics $(25,000-50,000$ patients) while $10 \%$ of type 2 diabetic ( 450,000 patients) regularly use insulin $(50,000$ patients) $[35,39]$. For the medical assistance of this population, there are in Portugal 175 endocrine specialists, 1,500 internal medicine specialists, 1,500 pediatricians $(10 \%$ with further training in diabetes) and 7,000 general physicians [35, 39].

\section{Patients and Methods}

All diabetic patients assisted by one of the authors, at the Diabetic Outpatient Department of Santa Maria Hospital, during the years of 2005 and 2006, were included in the study.

A specific database was defined using the Statistical Package for the Social Sciences Program, version 12.0 for Windows (SPSS, Inc., Chicago, Illinois). The following characteristics were included: 1) record number and name; 2) gender and age; 3) height and weight without shoes or coats at the first visit and at the last visit; from these the body mass index (BMI) was computed (BMI = weight $(\mathrm{kg}) /$ height $\left.(\mathrm{m})^{2}\right)$; 3) type of diabetes, according to the American Diabetes Association (ADA) and International Diabetes Federation criteria [4], but further distinguishing between 
Table 2. Rate of Microvascular Complications Across Diagnostic Categories

\begin{tabular}{lccc}
\hline & DM1 & DM2-IT & DM2-NIT \\
\hline Retinopathy (\%) & 33 & 53 & 29 \\
Cataracts (\%) & 6 & 60 & 44 \\
Nephropathy (\%) & 34 & 59 & 35 \\
Autonomic cystopathy (\%) & 5 & 21 & 7 \\
Autonomic gastroenteropathy (\%) & 7 & 3 & 3 \\
Peripheral neuropathy (\%) & 21 & 40 & 34 \\
Diabetic foot (\%) & 1 & 6 & 3 \\
\hline
\end{tabular}

type 2 patients regularly using insulin (insulin-treated, IT) or oral anti-diabetic agents (non-insulin-treated, NIT); 4) years since diagnosis; 5) blood pressure levels in the last visit; 5) retinopathy and/or cataracts according to specialized ophthalmologic observation; 6) nephropathy using the mean of the three last microalbuminuria determinations; 7) clinical evaluation of autonomic cystopathy, gastroenterologic dysautonomy and peripheral sensorimotor neuropathy or the diabetic foot; 8) presence or absence of high blood pressure (HBP), dyslipidemia, ischemic heart disease, cerebrovascular or peripheral artery disease by clinical evaluation using complementary methods when necessary; 9) diabetic medication currently used; 10) cardiovascular medication currently used; 11) dyslipidemia medication currently in use; 12) anti-platelet medication currently in use; 13) glycated hemoglobin $(\mathrm{HbA} 1 \mathrm{c})$, the last one and the first obtained during follow-up; 14) analytical evaluation in the last visit including glucose, cholesterol, triglycerides, HDLc, fibrinogen, C-reactive protein (CRP), erythrocyte sedimentation rate and homocysteine obtained after an overnight fast; 15) last endocrine analytical evaluation including serum $\mathrm{ACTH}$, cortisol, DHEAS, renin, aldosterone, C-peptide and $24 \mathrm{~h}$ urinary excretion of cortisol, C-peptide and aldosterone.

All analytic measurements were performed in the Clinical Pathology Laboratory of Santa Maria Hospital using standardized methodology. In brief glucose, cholesterol, triglycerides and HDLc were measured by automated enzymatic methods (Modular Analytics, F. Hoffmann-La Roche Ltd, Basel); HbA1c was measured by affinity chromatography (Primus Diagnostics, Kansas City); the erythrocyte sedimentation rate was measured by the Westgreen method (National Instruments Netherlands BV, Woerden), fibrinogen by the Emett-Claus method (F. Hoffmann-La Roche Ltd, Basel) and CRP using turbidometry (Horiba ABX, Montpellier); intra- and interassay coefficients of variation were less than $5 \%$ in every case. Enzyme immunoassay methods were used for the determination of ACTH, cortisol, DHEAS, C- peptide, homocysteine, and urinary cortisol, C-peptide and aldosterone (Diagnostic Products Corporation, Los Angeles) while radioimmunoassay methods were used for rennin and aldosterone measurements (Diagnostic Products Corporation, Los Angeles); intra- and interassay coefficients of variation were less than $10 \%$ in every case.

Results are presented as the mean \pm standard deviation or as percent as appropriate. Statistical analysis used the SPSS program. Results between groups were compared using the Student's t test or the $\chi^{2}$ test as appropriate as well as ANOVA. For multiple comparisons, the Bonferroni correction was used. The normal distribution of continuous variables was verified with the Kolmogorov-Smirnov test and non-normal distributed variables were log-transformed prior to further statistical analysis $[42,43]$.

\section{Results}

\section{Patient characteristics}

Nine hundred and seventy-one outpatient visits, regarding 271 patients occurred during the 2-year period (2005 and 2006). Yearly 94 new patients were admitted while 20 patients were lost for follow-up. The total number of visits represents $28 \%$ of the total of outpatient endocrine visits during the same period. During this period, 21 of these patients were admitted 26 times to the inpatient department. Patients were referred by their general physicians, although some were also referred form other departments of the hospital.

Forty-three patients $(16 \%)$ presented type 1 diabetes mellitus (DM1), 62 patients (23\%) presented type 2 diabetes mellitus and were regularly treated with insulin (DM2-IT), 152 patients $(56 \%)$ presented type 2 diabetes mellitus and were treated with oral anti-diabetic drugs (DM2-NIT), 12 patients (4\%) presented secondary diabetes mellitus (DMS) and two patients $(1 \%)$ presented maturity onset diabetes of 
Table 3. Rate of Macrovascular Disease Across Diagnostic Categories

\begin{tabular}{lccc}
\hline & DM1 & DM2-IT & DM2-NIT \\
\hline High blood pressure (\%) & 21 & 71 & 63 \\
Dyslipidemia (\%) & 50 & 66 & 63 \\
Ischemic heart disease (\%) & 2 & 16 & 17 \\
Cerebrovascular disease (\%) & 0 & 7 & 3 \\
Peripheral vascular disease (\%) & 7 & 31 & 27 \\
\hline
\end{tabular}

the young (MODY). Given the small number of patients with DMS and MODY, these patients were not included in the subsequent statistical analysis.

Patient characteristics are summarized in Table 1. Patients were middle-aged and mildly overweight. There were significantly more male patients in DM2-NIT, $\chi^{2}=7.6, \mathrm{df}=$ $2, \mathrm{P}<0.05,55 \%$ vs. $36 \%$, and DM1 patients were significantly younger, $\mathrm{F}(2,254)=90.761, \mathrm{P}<0.001,32 \pm 14$ years vs. $61 \pm 12$ years. Time since diagnosis was also significantly different across diagnostic groups, $\mathrm{F}(2,254)=10.223, \mathrm{P}<$ 0.001 , being significantly lower in DM2-NIT ( $9 \pm 8$ years vs. $14 \pm 9$ years $)$. DM1 patients were significantly leaner than either DM2 patients, $\mathrm{F}(2,254)=13.897, \mathrm{P}<0.001,23.1 \pm 3.8$ $\mathrm{kg} / \mathrm{m}^{2}$ vs. $29.1 \pm 5.4 \mathrm{~kg} / \mathrm{m}^{2}$. When referred to the outpatient department, metabolic control, considering $\mathrm{HbA1c}$, was less than optimal and differed significantly across diagnostic groups, $\mathrm{F}(2,241)=9.732, \mathrm{P}<0.001$, with post hoc analysis revealing higher values in both DM1 $(8.8 \pm 2.2 \%)$ and DM2IT $(9.3 \pm 2.0 \%)$ than in DM2-NIT $(8.0 \pm 1.7 \%)$.

The rate of clinically significant chronic microvascular complications across diagnostic groups is presented in Table 2. Retinopathy $\left(\chi^{2}=8.7, \mathrm{df}=2, \mathrm{P}<0.05\right)$, cataracts $\left(\chi^{2}=\right.$ $26.2, \mathrm{df}=2, \mathrm{P}<0.005)$, nephropathy $\left(\chi^{2}=12.5, \mathrm{df}=2, \mathrm{P}<\right.$ $0.05)$ and autonomic cystopathy $\left(\chi^{2}=11.8, \mathrm{df}=2, \mathrm{P}<0.05\right)$ were always more common in DM2-IT, with no differences between DM1 or DM2-NIT patients, except for cataracts also more common in DM2-NIT patients. There were no differences regarding autonomic gastroenteropathy, peripheral

Table 4. Selected Biochemical Parameters Across Diagnostic Groups

\begin{tabular}{lccc}
\hline & DM1 & DM2-IT & DM2-NIT \\
\hline VS (mm) & $11 \pm 9$ & $34 \pm 31$ & $13 \pm 23$ \\
CRP $(\mathrm{mg} / \mathrm{dL})$ & $0.25 \pm 0.47$ & $0.54 \pm 0.64$ & $0.43 \pm 0.54$ \\
Homocysteine $(\mu \mathrm{mol} / \mathrm{L})$ & $7 \pm 2$ & $12 \pm 6$ & $13 \pm 5$ \\
Fibrinogen $(\mathrm{mg} / \mathrm{dL})$ & $320 \pm 56$ & $369 \pm 53$ & $342 \pm 135$ \\
ACTH $(\mathrm{pg} / \mathrm{mL})$ & $23 \pm 15$ & $23 \pm 14$ & $22 \pm 12$ \\
Cortisol $(\mu \mathrm{g} / \mathrm{dL})$ & $19 \pm 7$ & $16 \pm 8$ & $20 \pm 7$ \\
Renin $(\mathrm{pg} / \mathrm{mL})$ & $19 \pm 10$ & $27 \pm 19$ & $26 \pm 34$ \\
Aldosterone $(\mathrm{pg} / \mathrm{mL})$ & $124 \pm 117$ & $106 \pm 73$ & $106 \pm 66$ \\
C-peptide $(\mathrm{ng} / \mathrm{mL})$ & $0.9 \pm 0.5$ & $1.9 \pm 0.9$ & $2.8 \pm 1.3$ \\
Cortisol $(\mu \mathrm{g}, 24 \mathrm{~h}$ urine) & $78 \pm 39$ & $109 \pm 49$ & $91 \pm 43$ \\
Aldosterone $(\mu \mathrm{g}, 24 \mathrm{~h}$ urine) & $18 \pm 20$ & $20 \pm 29$ & $14 \pm 20$ \\
C-peptide $(\mu \mathrm{g}, 24 \mathrm{~h}$ urine) & $15 \pm 26$ & $56 \pm 59$ & $93 \pm 56$ \\
\hline
\end{tabular}




\section{Pharmacological regimens in DM1 patients}

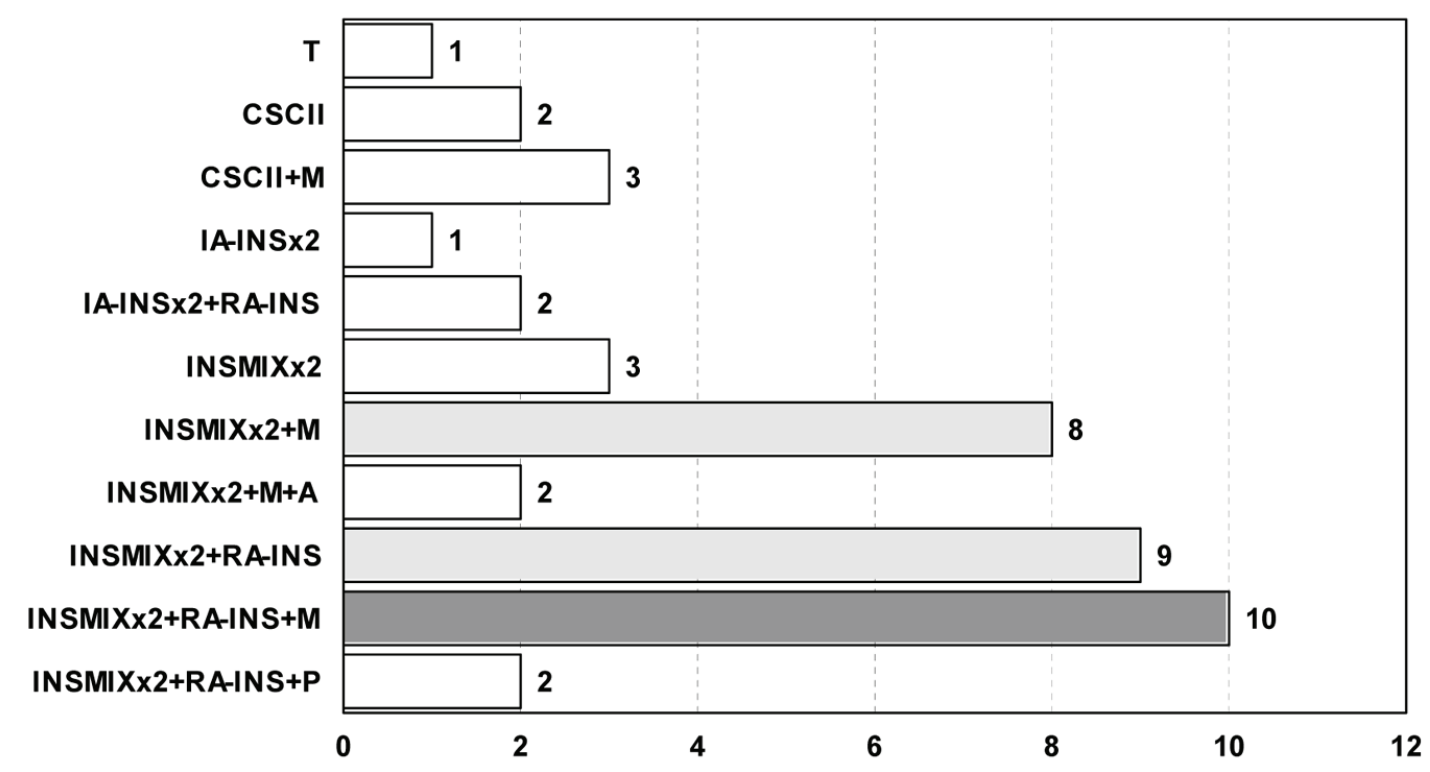

Figure 1. Pharmacological regimens in DM1 patients. T: pancreas transplant; CSCII: continuous subcutaneous insulin infusion; IA-INS: intermediate acting insulin; RA-INS: rapid acting insulin; INSMIXT: pre-mixed insulin with intermediate acting insulin and 10, 20 or $30 \%$ of rapid acting insulin; M: metformin; P: pioglitazone; A: acarbose; S: sulphonylurea; NT: nateglinide; N: without pharmacological drug therapy. Number of patients with each regimen is presented in the horizontal axis. The most common regime is filled dark gray and the other common regimens are filled light gray.

neuropathy or the diabetic foot.

In Table 3, the rate of clinically significant macrovascular disease across diagnostic groups is presented. $\operatorname{HBP}\left(\chi^{2}=\right.$ $30.2, \mathrm{df}=2, \mathrm{P}<0.001)$, ischemic heart disease $\left(\chi^{2}=6.0, \mathrm{df}\right.$ $=2, \mathrm{P}<0.05)$ and peripheral vascular disease $\left(\chi^{2}=9.2, \mathrm{df}=\right.$ $2, \mathrm{P}<0.01)$ were significantly less common in DM1 patients, with no differences between DM2-IT and DM2-NIT. No differences could be found regarding dyslipidemia or cerebrovascular disease.

Table 4 presents selected biochemical parameters across diagnostic groups. Homocysteine, a common marker of endothelial dysfunction was significantly higher in both DM2IT and DM2-NIT, F(2,224) $=12.389, \mathrm{P}<0.001,13 \pm 6$ vs. 7 \pm 2 . No differences could be found regarding common markers of the inflammatory processes. Serum C-peptide and the $24 \mathrm{~h}$ urinary excretion of C-peptide were significantly different across all diagnostic groups, $\mathrm{F}(2,206)=10.815, \mathrm{P}<$ 0.001 and $\mathrm{F}(2,215)=16.296, \mathrm{P}<0.001$. The $24 \mathrm{~h}$ cortisol urinary excretion was significantly increased in DM2-IT patients compared with the other groups, $\mathrm{F}(2,227)=2.812, \mathrm{P}<$ $0.05,109 \pm 49$ vs. $88 \pm 42$.

\section{Therapeutic regimens}

Therapeutic regimens varied widely in each diagnostic group. In every case, patients were carefully instructed regarding an adequate meal plan, and an appropriate exercise schedule. Also, in every case patients followed a regular plan for self-monitoring of blood glucose.

Therapeutic regimens used in DM1, DM2-IT and DM2NIT patients are presented in Figures 1-3.

Regarding DM1 patients, the majority of the patients used intermediate-acting or insulin mixtures twice daily, before breakfast and before dinner/supper, with half of them also using rapid-acting insulin before lunch; half of the patients were also using metformin twice/thrice daily. Six patients used the continuous subcutaneous insulin infusion system.

DM2-IT patients were treated with intermediate-acting or insulin mixtures twice daily, before breakfast and before dinner/supper, and $20 \%$ were also taking rapid-acting insulin before lunch. Seventy-five percent of the patients were also taking metformin twice or thrice daily. One patient used the continuous subcutaneous insulin infusion system.

Most of DM2-NIT patients were treated with two different drugs, generally metformin and a sulfonylurea $(68 \%)$.

Two-thirds (67\%) of the patients were under HBP medication; however, the distribution was significantly different across diagnostic groups, $\chi^{2}=47.3, \mathrm{df}=2, \mathrm{P}<0.001,89 \%$ in DM2-IT patients, $71 \%$ in DM2-NIT patients and $26 \%$ 


\section{Pharmacological regimens in DM2-IT patients}

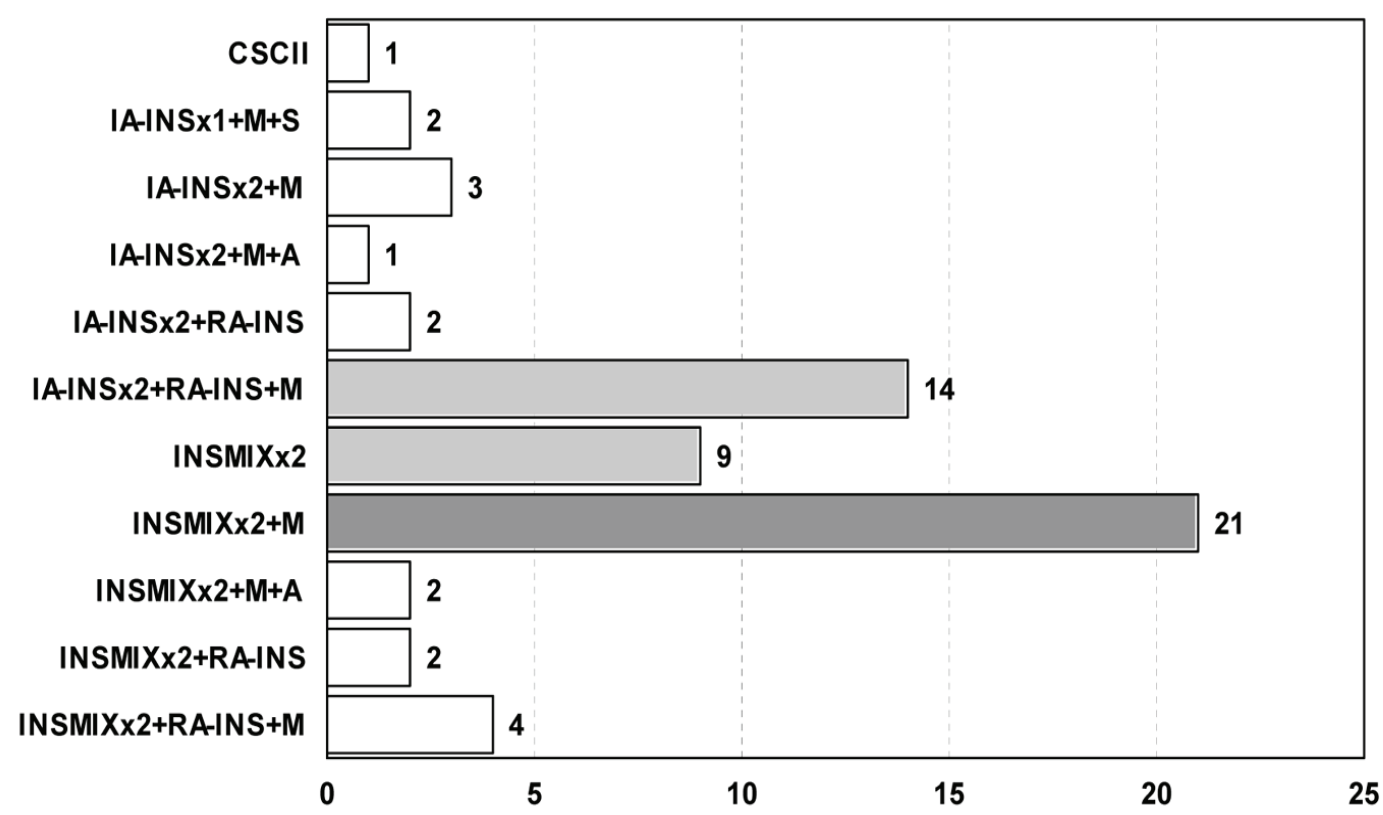

Figure 2. Pharmacological regimens in DM2-IT patients. T: pancreas transplant; CSCII: continuous subcutaneous insulin infusion; IA-INS: intermediate acting insulin; RA-INS: rapid acting insulin; INSMIXT: pre-mixed insulin with intermediate acting insulin and 10,20 or $30 \%$ of rapid acting insulin; M: metformin; P: pioglitazone; A: acarbose; S: sulphonylurea; NT: nateglinide; N: without pharmacological drug therapy. Number of patients with each regimen is presented in the horizontal axis. The most common regime is filled dark gray and the other common regimens are filled light gray.

in DM1 patients. Monotherapy was used in $49 \%$ of these patients and the class of angiotensin converting enzyme inhibitors was used in $80 \%$ of these. In $21 \%$ of the patients under therapy, double therapy was used with angiotensin converting enzyme inhibitors being used in 70\% and angiotensin receptor antagonists in 30\%, although both were used in only $8 \% ; 20 \%$ were using three or more drugs to lower blood pressure.

Less than half $(41 \%)$ of the patients were prescribed lipid-lowering drugs, and again the distribution was significantly different across diagnostic groups, $\chi^{2}=13.3, \mathrm{df}=2$, $\mathrm{P}<0.001,47 \%$ in DM2-IT patients, $46 \%$ in DM2-NIT patients and $16 \%$ in DM1 patients. Of these two-thirds were using statins as monotherapy while $1 \%, 3 \%$ and $3 \%$ used fibrates, nicotinic acid or ezetimibe. Eighteen percent were using double therapy with statin and fibrate being the choice in $84 \%$ of these patients.

Two-thirds of the patients were using anti-platelet agents again with significant differences across diagnostic groups, $\chi^{2}=45.3$, df $=2, \mathrm{P}<0.001,82 \%$ in DM2-IT patients, $73 \%$ in DM2-NIT patients and $23 \%$ in DM1 patients. In $82 \%$ of these, low dose acetylsalicylic acid (100 - $150 \mathrm{mg})$ was being used.

\section{Results}

At their last visit, metabolic control, judged by $\mathrm{HbA} 1 \mathrm{c}$ is still far from optimal, $8.0 \pm 1.9 \%$, with significant differences across diagnostic groups, $\mathrm{F}(2,243)=8.053, \mathrm{P}<0.001,9.3$ $\pm 2.4 \%$ in DM1 patients, $8.6 \pm 1.6 \%$ in DM2-IT patients and $7.4 \pm 1.6 \%$ in DM2-NIT patients, the differences being significantly between all groups (Table 5). Paired t-test analysis showed that $\mathrm{HbA} 1 \mathrm{c}$ significantly decreased from the first to the last visit, from $8.5 \pm 2.0 \%$ to $8.1 \pm 1.9 \%, \mathrm{t}=-3.177$, $\mathrm{df}=$ $235, \mathrm{P}<0.005$, although when individual diagnostic groups were considered, the difference was not significant in DM1 patients.

When all patients were considered together, no significant weight change was found between the first and the last visit; however, when diagnostic groups were individually analyzed, a significant weight gain was found both in DM1 and DM2-IT patients, $\mathrm{t}=2.045$ and 2.390, $\mathrm{df}=39$ and 57, $\mathrm{P}$ $<0.05$, while a significant weight loss occurred in DM2-NIT patients, $\mathrm{t}=1.970, \mathrm{df}=141, \mathrm{P}<0.05$.

Both systolic and diastolic blood pressure levels differed significantly between diagnostic groups at the last visit, $\mathrm{F}(2,244)=14.501$ and $\mathrm{F}(2,244)=5.85, \mathrm{P}<0.005$, with sig- 


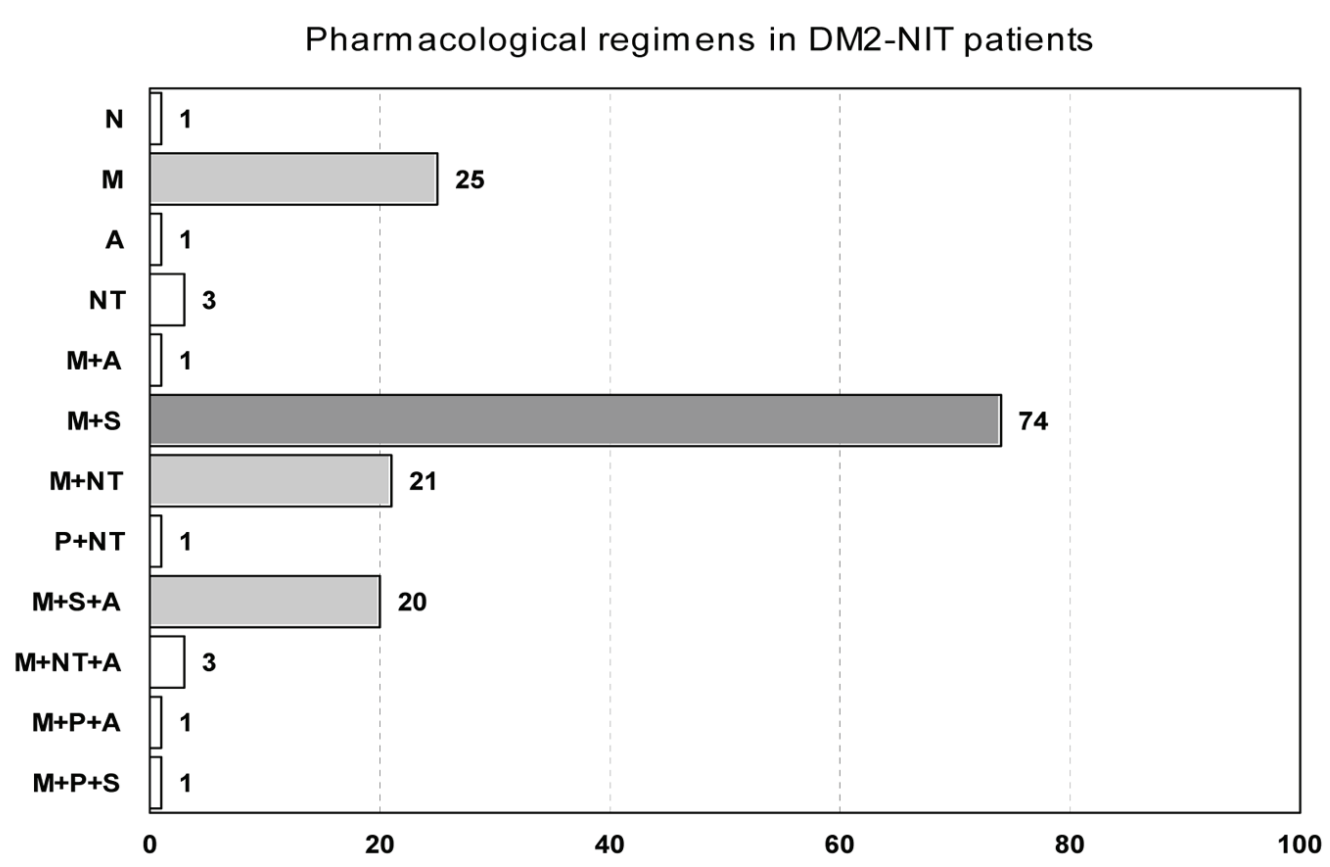

Figure 3. Pharmacological regimens in DM2-NIT patients. T: pancreas transplant; CSCII: continuous subcutaneous insulin infusion; IA-INS: intermediate acting insulin; RA-INS: rapid acting insulin; INSMIXT: pre-mixed insulin with intermediate acting insulin and 10,20 or $30 \%$ of rapid acting insulin; M: metformin; P: pioglitazone; A: acarbose; S: sulphonylurea; NT: nateglinide; N: without pharmacological drug therapy. Number of patients with each regimen is presented in the horizontal axis. The most common regime is filled dark gray and the other common regimens are filled light gray.

nificantly lower levels in DM1 patients and no differences between DM2 patients. Almost half of the DM2 patients presented systolic blood pressure levels above current recommendations.

Although serum cholesterol levels did not differ significantly across diagnostic groups, in DM1 patients, serum triglyceride levels were significantly lower, $\mathrm{F}(2,241)=2.893$, $\mathrm{P}<0.06$, and serum HDLc levels were significantly higher, $\mathrm{F}(2,240)=5.164, \mathrm{P}<0.01$, than in either DM2 group.

\section{Discussion}

Unless dramatic epidemiologic changes or scientific breakthroughs occur, in the 21 st century, diabetes mellitus will be one of the most common chronic serious disorders, making up a major fraction of general physician, internist and endocrinologist activity, and pervading all other medical specialities [1-3]. Both, the increasing incidence of diabetes and the recently documented decreased mortality of diabetic patients, will contribute [1].

At current estimates, in $10-20$ years, there will be 800,000 diabetic patients in Portugal, consuming around $20 \%$ of Public Health resources [1-3, 35, 39, 44]. From these about $10 \%$ will be type 1 diabetic patients and maybe another $10 \%$ type 2 diabetic patients requiring insulin. Both groups require specialized and multidisciplinary assistance
[4]; since each diabetic patient must be seen, at least 3-4 times a year, for an hospital-based endocrine specialist with 2,000 visits/year, and diabetics comprising $30 \%$ of the practice, a theoretical ceiling of around 200 patients can be assisted [44].

For reasons stated above, the medical assistance of diabetic patients is a complex, challenging and time-consuming task [4]. Scientific evidence, incorporated in professional recommendations, objectively and clearly defines multiple goals, at different levels, for example, metabolic control, blood pressure and lipid management, prevention of cardiovascular disease, eye, kidney, foot and dental care, common infectious diseases prophylaxis, notwithstanding patient wellbeing, empowerment and social integration [4]. Although scientific evidence is sound, it remains to be seen how these recommendations are incorporated in the real conditions of medical practice. Still another problem would be to acknowledge the constraints that these impose on the patients, and to evaluate their adherence to the medical plan.

The next step after careful medical assistance is to define and update adequate databases of clinical records. This allows for the objective and inter-center evaluation and comparison of medical assistance. More importantly, this is fundamental to identify critical issues and to advance scientific knowledge. These are the objectives of the present report.

Santa Maria Hospital, in Lisbon, Portugal, is a tertiary medical center with an associated medical school. Diabeto- 
Table 5. Results of Medical Treatment

\begin{tabular}{lccc}
\hline & DM1 & DM2-IT & DM2-NIT \\
& & & \\
\hline HbA1c $(\%)$ & $9.3 \pm 2.4$ & $8.6 \pm 1.6$ & $7.4 \pm 1.6$ \\
HbA1c $<7 \%(\%)$ & 8 & 15 & 45 \\
HbA1c $<8 \%(\%)$ & 30 & 34 & 71 \\
$\Delta$ HbA1c (first-last visit) & $-0.4 \pm 2.3$ & $0.7 \pm 1.8$ & $0.6 \pm 1.7$ \\
Serum glucose (mg/dL) & $181 \pm 93$ & $169 \pm 81$ & $157 \pm 65$ \\
$\Delta$ weight $(\mathrm{kg})($ first-last visit) & $-2 \pm 7$ & $-2 \pm 5$ & $1 \pm 4$ \\
SBP $(\mathrm{mmHg})$ & $117 \pm 24$ & $136 \pm 16$ & $136 \pm 21$ \\
SBP $\leq 130$ mmHg (\%) & 84 & 53 & 55 \\
DBP (mmHg) & $65 \pm 13$ & $72 \pm 9$ & $73 \pm 14$ \\
DBP $\leq 80$ mmHg (\%) & 88 & 89 & 84 \\
Serum cholesterol (mg/dL) & $192 \pm 60$ & $195 \pm 38$ & $191 \pm 42$ \\
Serum cholesterol $\leq 200 \mathrm{mg} / \mathrm{dL}(\%)$ & 75 & 64 & 64 \\
Serum triglycerides (mg/dL) & $114 \pm 160$ & $169 \pm 96$ & $152 \pm 90$ \\
Serum triglycerides $\leq 150 \mathrm{mg} / \mathrm{dL}(\%)$ & 89 & 51 & 58 \\
Serum HDLc (mg/dL) & $66 \pm 22$ & $56 \pm 26$ & $54 \pm 17$ \\
Serum HDL $\geq 45 \mathrm{mg} / \mathrm{dL}(\%)$ & 72 & 63 \\
\hline & & & \\
\hline
\end{tabular}

SBP: systolic blood pressure; DBP: diastolic blood pressure.

logic assistance has a long-standing record in the hospital and medical school. The assistant team includes specialized medical doctors, nurses, nutritions/dietitians and psychologists. Institutional collaboration with other medical specialities within the hospital, like ophthalmology, nephrology, cardiology, neurology and vascular surgery is well established. It comprises the full spectrum of medical assistance to diabetic patients, including emergency assistance, inpatient clinic, obstetric and pediatric assistance and health education. For a long time, the department has regularly collaborated with the General Physicians of the Lisbon area and is responsible for the undergraduate and post-graduate education within the medical school.

It is within the above mentioned setting that presented results must be considered. Although data relate to a single medical doctor, with the advantage of uniformity, results largely reflect the medical assistance of the diabetic team.

A total of almost 300 patients, were assisted, generally with 3-4 visits/year. Drops-outs from the clinic were rare, contrasting to what occurs in other diseases [45]. The distribution across diagnostic categories, as defined, is still not adequate with less than desirable rates of DM1 and DM2IT and too many DM2-NIT patients. Patients were mainly referred by their general physicians, except DM1 patients, previously assisted at the pediatric department or at other institutions. In either case, long-standing diabetes was already present, grossly diminished insulin reserve was present in DM2-IT patients and the metabolic control was poor, mainly in DM1 and DM2-IT patients. Age differences were as expected.

More than $75 \%$ of the DM2 patients were either obese or overweight; this is well recognized and emphasizes the importance of obesity and insulin resistance in the pathogenesis of type 2 diabetics [32, 33]; however, since almost half were only overweight, it seems slight excess body weight may be enough, even in the absence of obesity [46]. On the other side in DM1 patients the rate of obesity is markedly less than what can be found in the general population.

In this group of diabetic patients, with long-standing disease and less than optimal metabolic control, microvascular target organ disease is common. Some of these, like autonomic and peripheral neuropathy lack simple and objective assessment methods, and true frequency may be different from that reported [47]. Curiously enough, although time since diagnosis is not markedly different across diagnostic groups, and age is not markedly different between type 2 dia- 
betic patients, these complications are much more frequently in DM2-IT patients, suggesting the importance of residual $\beta$-cell function and aging.

Again in this group of patients, HBP and dyslipidemia are common, but the rate of dyslipidemia is not significantly different across diagnostic groups and is for the most part hypercholesterolemia, not hypertriglyceridemia [48]. Clinically significant cardiovascular disease is not however very common, except for peripheral vascular disease, arguing for the lack of sensitivity/specificity of clinical evaluation. Again cardiovascular risk factors and established cardiovascular disease are more common in DM2-IT patients, suggesting the importance of $\beta$-cell function and aging. This same effect of aging and residual $\beta$-cell function, is also apparent regarding markers of the inflammatory process (more common in the DM2-IT group) [49-52].

Pharmacological treatment in this group of selected patients presents some distinctive features. In the DM1 group, only about half of the patients, are under intensive treatment including those using the continuous subcutaneous insulin infusion system; on the other hand, half of the patients are using drugs to correct insulin resistance; these data may be open to discussion [4]. These characteristics are even more marked in the DM2-IT group. Most of the patients of the DM2-NIT group are under combined treatment with drugs to correct insulin resistance and classical or new secretagogs. Some "old" drugs, like acarbose, new drugs like glitinides, glitazones and DPP-IV inhibitors, or new formulations of classical drugs like inhaled insulin are only marginally used or not at all, and this may also be open to discussion [4].

Pharmacological treatment of HBP and/or nephropathy seems adequately prescribed; however, half of the patients were under monotherapy and this may fall off the target [4, 53]. Under treatment of dyslipidemia is apparent given the difference between reported rates of dyslipidemia and the rate of patients using lipid-lowering drugs [54]. The most common dyslipidemia is hypercholesterolemia, like in the general population, explaining the wide use of statins [48, 54]. More specifically under treatment of mild forms of hypertriglyceridemia and/or low HDLc seems to occur. Antiplatelet agents, mostly low dose acethylsalicilic acid, was widely used as recommended $[4,55]$.

Results are somehow disappointing.

Metabolic control is far from acceptable, mainly in DM1 and DM2-IT patients, and since referral, it did not improve in DM1 patients, decreasing only slightly in DM2-IT and DM2-NIT patients. Furthermore, HbA1c does not completely reflect the degree of metabolic control, with the extent of posprandial glycemic excursions and glycemic variability being also significant factors and these were not specifically evaluated [56]. Systolic blood pressure is not adequately controlled in DM2 patients, although diastolic blood pressure is [54]. Dyslipidemia persists in almost half of DM2 patients [55].
These results may be compared with those reported in the literature.

Special conditions of course characterize prospective clinical trials.

In the DCCT, regarding DM1 patients, followed for a mean of 6.5 years, patients under conventional treatment, one or two daily injections of insulin, were compared with those under intensive therapy, administration of insulin three or more times daily. Mean $\mathrm{HbAlc}$ was around $9 \%$ in the first group and around 7\% in the second one, in fact at the end of the study $9.1 \%$ vs. $7.4 \%$ [7]. At the end of the study only $3-4 \%$ of the patients had hypertension and only $26-30 \%$ had dyslipidemia [7]. More interestingly, 11 years after, now treated by their own health care providers, mean $\mathrm{HbA} 1 \mathrm{c}$ was $7.9 \%, 40 \%$ had hypertension and 50\% had dyslipidemia [9].

In the UKPDS, regarding newly diagnosed DM2 patients, followed for 10 years, conventional treatment was compared with intensive treatment. Mean $\mathrm{HbA1c}$ was $7.9 \%$ vs. $7.0 \%$, in fact around $9 \%$ and $8 \%$, respectively at the end of the study. Mean blood pressure levels (excluding patients under chlorpropamide treatment) were $138 / 80$ at 6 years of follow-up [10].

Those results may be contrasted with those of more real medical practice conditions.

Comparing metabolic control in 18 countries in Europe, Japan and North America, Mortensen et al [57] found that DM1 patients assisted at pediatric centers presented a mean $\mathrm{HbA} 1 \mathrm{c}$ of $8.6 \%$, with $34 \%$ of the patients presenting values $<8 \%$. As noted by the authors, these were specialized multidisciplinary health care centers, and these patients probably represented the best-managed patients in those countries.

According to the Swedish National Diabetes Register, and regarding type 1 diabetic patients, mean $\mathrm{HbAlc}$ was $8.0 \%$, with $21 \%$ of the patients presenting values $<7 \%$; the proportion of the patients using anti-hypertensive drugs was $34 \%$ with a mean blood pressure of $129 / 74 \mathrm{mmHg}$, and $39 \%$ of them presenting values below $139 / 80 \mathrm{mmHg}, 25 \%$ were using lipid-lowering drugs, with mean values for total cholesterol and triglycerides of $184 \mathrm{mg} / \mathrm{dL}$ and $99 \mathrm{mg} / \mathrm{dL}$, while $17 \%$ of the patients were using aspirin. Interestingly enough, the vast majority of the patients were treated by specialists in diabetology, endocrinology or internal medicine, with specialist nurses and dietitians, and continuous subcutaneous insulin infusions were used by $14 \%$ of the patients [58].

Some general data regarding diabetic subjects, mostly reflect DM2 patients. In the Diabetes Quality Improvement Project, using data from the National Health and Nutrition Examination Survey (NHANES III) from 1988-1994 and the Behavioral Risk Factors Surveillance System from 1,195 diabetic subjects aged $18-75$, median $\mathrm{HbAlc}$ was $7.5 \%$ with less than half (43\%) with values below $7 \%$, median systolic blood pressure levels of $131 \mathrm{mmHg}$ with $30 \%$ presenting values above $140 \mathrm{mmHg}$, median LDLc of $134 \mathrm{mg} / \mathrm{dL}$, with more than half of the subjects with values above $130 \mathrm{mg} /$ 
dL. Only $38 \%$ of the subjects monitored their blood glucose level at least once daily, only $46 \%$ received influenza vaccine last year, and only $27 \%$ ever received the pneumococcal vaccine [59].

Using more recent data from the National Health and Nutrition Examination Survey (NHANES) 1999-2002, regarding self-reported diabetic subjects, of whom $41 \%$ had the disease for more than 10 years, $27 \%$ were taking insulin, and $18 \%$ were not using drugs for diabetes, Resnick et al [60] found a mean BMI of $31.8 \mathrm{~kg} / \mathrm{m}^{2}$, with a waist circumference of $109 \mathrm{~cm}$ in men and $106 \mathrm{~cm}$ in women. Mean values for relevant biochemical parameters were fasting serum glucose, $150 \mathrm{mg} / \mathrm{dL}$, and fasting total cholesterol, 204 $\mathrm{mg} / \mathrm{dL}$. Regarding ADA clinical practice recommendations 2001, 50\% presented HBA1c $<7 \%$, and $21 \%$ presented HbAlc between 7 and $8 \%$. Proportion of diabetic subjects achieving LDL $(<100 \mathrm{mg} / \mathrm{dL})$, triglycerides $(<200 \mathrm{mg} / \mathrm{dL})$, HDL ( $>45 \mathrm{mg} / \mathrm{dl}$ for males and $>55 \mathrm{mg} / \mathrm{dL}$ for females) and blood pressure targets $(<130 / 80)$ were $36 \%, 65 \%, 27 \%$ and $40 \%$, respectively.

In a national population-based survey of Australian adults with DM2, the proportion of subjects reaching targets for $\mathrm{HbA} 1 \mathrm{c}(<7 \%)$, total cholesterol $(<210 \mathrm{mg} / \mathrm{dL})$ and blood pressure $(<140 / 90 \mathrm{mmHg})$ were $57 \%, 53 \%$ and $46 \%$, respectively; all three targets were only reached by $13 \%$ of the subjects (or $2 \%$ considering the more stringent ADA 2004 criteria) [61].

In short, referral to a tertiary hospital center for the assistance of diabetic patients is still far from what it should be. Patients however, as expected, have long-standing disease and mediocre metabolic control. Micro- and macrovascular disease is common particularly so in DM2-IT patients. $\beta$-cell function and aging seem to be the relevant factors underlying clinical evolution, and in this regard, DM2-IT presents the most difficult management problems. Complex multifactorial assistance is used but fails short of intensive treatment. Metabolic control remains poor, systolic blood pressure remains high and dyslipidemia is not fully corrected. Even so, the burden of the disease and of the associated medical management must be very high for the patient, and adherence is probably low, although it was not specifically evaluated.

There is of course substantial opportunity for improvement. However, some previous attempts, for instance structured personal care (for patients) or educational outreach (for doctors) have only obtained limited results at the best. A more radical analysis would suggest the need for system change, and the search for new paradigms of health care [62].

\section{Declaration}

All authors declare no conflict of interest regarding the submitted work.

\section{References}

1. King H, Aubert RE, Herman WH. Global burden of diabetes, 1995-2025: prevalence, numerical estimates, and projections. Diabetes Care. 1998;21(9):1414-1431.

2. Zimmet P, Alberti KG, Shaw J. Global and societal implications of the diabetes epidemic. Nature. 2001;414(6865):782-787.

3. Narayan KM, Boyle JP, Geiss LS, Saaddine JB, Thompson TJ. Impact of recent increase in incidence on future diabetes burden: U.S., 2005-2050. Diabetes Care. 2006;29(9):2114-2116.

4. American Diabetes A. Standards of medical care in diabetes--2007. Diabetes Care. 2007;30(Suppl 1):S4-S41.

5. Johnson JA, Pohar SL, Majumdar SR. Health care use and costs in the decade after identification of type 1 and type 2 diabetes: a population-based study. Diabetes Care. 2006;29(11):2403-2408.

6. Rathmann W, Haastert B, Icks A, Giani G. Trends in outpatient prescription drug costs in diabetic patients in Germany, 1994-2004. Diabetes Care. 2007;30(4):848853.

7. The effect of intensive treatment of diabetes on the development and progression of long-term complications in insulin-dependent diabetes mellitus. The Diabetes Control and Complications Trial Research Group. N Engl J Med. 1993;329(14):977-986.

8. Retinopathy and nephropathy in patients with type 1 diabetes four years after a trial of intensive therapy. The Diabetes Control and Complications Trial/Epidemiology of Diabetes Interventions and Complications Research Group. N Engl J Med. 2000;342(6):381-389.

9. Nathan DM, Cleary PA, Backlund JY, Genuth SM, Lachin JM, Orchard TJ, Raskin P, et al. Intensive diabetes treatment and cardiovascular disease in patients with type 1 diabetes. N Engl J Med. 2005;353(25):26432653.

10. Intensive blood-glucose control with sulphonylureas or insulin compared with conventional treatment and risk of complications in patients with type 2 diabetes (UKPDS 33). UK Prospective Diabetes Study (UKPDS) Group. Lancet. 1998;352(9131):837-853.

11. Effect of intensive blood-glucose control with metformin on complications in overweight patients with type 2 diabetes (UKPDS 34). UK Prospective Diabetes Study (UKPDS) Group. Lancet. 1998;352(9131):854-865.

12. Pan XR, Li GW, Hu YH, Wang JX, Yang WY, An ZX, $\mathrm{Hu} \mathrm{ZX}$, et al. Effects of diet and exercise in preventing NIDDM in people with impaired glucose tolerance. The Da Qing IGT and Diabetes Study. Diabetes Care. 1997;20(4):537-544.

13. Tuomilehto J, Lindstrom J, Eriksson JG, Valle TT, Hamalainen H, Ilanne-Parikka P, Keinanen-Kiukaanniemi S, et al. Prevention of type 2 diabetes mellitus by changes 
in lifestyle among subjects with impaired glucose tolerance. N Engl J Med. 2001;344(18):1343-1350.

14. Knowler WC, Barrett-Connor E, Fowler SE, Hamman RF, Lachin JM, Walker EA, Nathan DM, et al. Reduction in the incidence of type 2 diabetes with lifestyle intervention or metformin. N Engl J Med. 2002;346(6):393403.

15. Diabetes Prevention Program Research G. Effects of withdrawal from metformin on the development of diabetes in the diabetes prevention program. Diabetes Care. 2003;26(4):977-980.

16. Ratner R, Goldberg R, Haffner S, Marcovina S, Orchard $\mathrm{T}$, Fowler S, Temprosa M, et al. Impact of intensive lifestyle and metformin therapy on cardiovascular disease risk factors in the diabetes prevention program. Diabetes Care. 2005;28(4):888-894.

17. Chiasson JL, Josse RG, Gomis R, Hanefeld M, Karasik A, Laakso M, Group S-NTR. Acarbose for prevention of type 2 diabetes mellitus: the STOP-NIDDM randomised trial. Lancet. 2002;359(9323):2072-2077.

18. Chiasson JL, Josse RG, Gomis R, Hanefeld M, Karasik A, Laakso M, Group S-NTR. Acarbose treatment and the risk of cardiovascular disease and hypertension in patients with impaired glucose tolerance: the STOP-NIDDM trial. JAMA. 2003;290(4):486-494.

19. Buchanan TA, Xiang AH, Peters RK, Kjos SL, Marroquin A, Goico J, Ochoa C, et al. Preservation of pancreatic beta-cell function and prevention of type 2 diabetes by pharmacological treatment of insulin resistance in high-risk hispanic women. Diabetes. 2002;51(9):27962803.

20. Torgerson JS, Hauptman J, Boldrin MN, Sjostrom L. XENical in the prevention of diabetes in obese subjects (XENDOS) study: a randomized study of orlistat as an adjunct to lifestyle changes for the prevention of type 2 diabetes in obese patients. Diabetes Care. 2004;27(1):155-161.

21. Nathan DM, Lachin J, Cleary P, Orchard T, Brillon DJ, Backlund JY, O'Leary DH, et al. Intensive diabetes therapy and carotid intima-media thickness in type 1 diabetes mellitus. N Engl J Med. 2003;348(23):2294-2303.

22. Efficacy of atenolol and captopril in reducing risk of macrovascular and microvascular complications in type 2 diabetes: UKPDS 39. UK Prospective Diabetes Study Group. BMJ. 1998;317(7160):713-720.

23. Tight blood pressure control and risk of macrovascular and microvascular complications in type 2 diabetes: UKPDS 38. UK Prospective Diabetes Study Group. BMJ. 1998;317(7160):703-713.

24. Yusuf S, Sleight P, Pogue J, Bosch J, Davies R, Dagenais $\mathrm{G}$. Effects of an angiotensin-converting-enzyme inhibitor, ramipril, on cardiovascular events in high-risk patients. The Heart Outcomes Prevention Evaluation Study Investigators. N Engl J Med. 2000;342(3):145-
153.

25. Investigators DT, Bosch J, Yusuf S, Gerstein HC, Pogue J, Sheridan P, Dagenais G, et al. Effect of ramipril on the incidence of diabetes. N Engl J Med. 2006;355(15):15511562.

26. Pyorala K, Pedersen TR, Kjekshus J, Faergeman O, Olsson AG, Thorgeirsson G. Cholesterol lowering with simvastatin improves prognosis of diabetic patients with coronary heart disease. A subgroup analysis of the Scandinavian Simvastatin Survival Study (4S). Diabetes Care. 1997;20(4):614-620.

27. Collins R, Armitage J, Parish S, Sleigh P, Peto R, Heart Protection Study Collaborative G. MRC/BHF Heart Protection Study of cholesterol-lowering with simvastatin in 5963 people with diabetes: a randomised placebo-controlled trial. Lancet. 2003;361(9374):2005-2016.

28. Colhoun HM, Betteridge DJ, Durrington PN, Hitman GA, Neil HA, Livingstone SJ, Thomason MJ, et al. Primary prevention of cardiovascular disease with atorvastatin in type 2 diabetes in the Collaborative Atorvastatin Diabetes Study (CARDS): multicentre randomised placebo-controlled trial. Lancet. 2004;364(9435):685-696.

29. Brown BG, Zhao XQ, Chait A, Fisher LD, Cheung MC, Morse JS, Dowdy AA, et al. Simvastatin and niacin, antioxidant vitamins, or the combination for the prevention of coronary disease. N Engl J Med. 2001;345(22):15831592.

30. Hansson L, Zanchetti A, Carruthers SG, Dahlof B, Elmfeldt D, Julius S, Menard J, et al. Effects of intensive blood-pressure lowering and low-dose aspirin in patients with hypertension: principal results of the Hypertension Optimal Treatment (HOT) randomised trial. HOT Study Group. Lancet. 1998;351(9118):1755-1762.

31. Force USPST. Aspirin for the primary prevention of cardiovascular events: recommendation and rationale. Ann Intern Med. 2002;136(2):157-160.

32. Vague J. Obesities. John Libbey \& Company Ltd, London, 1991.

33. Ferrannini E, Buzzigoli G, Bonadonna R, Giorico MA, Oleggini M, Graziadei L, Pedrinelli R, et al. Insulin resistance in essential hypertension. $\mathrm{N}$ Engl J Med. 1987;317(6):350-357.

34. Reaven GM. Banting lecture 1988. Role of insulin resistance in human disease. Diabetes. 1988;37(12):15951607.

35. Martin Martins J, do Vale S. Endocrinologia Hospital - esboco de analise. Endocrinol Metab \& Nutr. 2004;13:81-104.

36. Barreto A, Valadas Preto C, Valente Rosa MJ, Costa Lobo M, Chitas P. A situacao social em Portugal 19601999. Indicadores sociais em Portugal e na Uniao Europeia. Imprensa das Ciencias Sociais, Lisboa, 2000.

37. Eurostat Yearbook. The statistical guide to Europe. Office for Official Publications of the European Communi- 
ties, Luxembourg. 2001.

38. Eurostat. The social situation in the European Union. Office for Official Publications of the European Communities, Luxembourg, 2001

39. Instituto Nacional de Estatistica. Estatisticas da saude 2000. Instituto Nacional de Estatistica, Lisboa, 2002.

40. Villaverde Cabral M, Alcantara da Silva P, Mendes H. Saude e doenca em Portugal. Imprensa das Ciencias Sociais, Lisboa, 2002.

41. Health care Systems in transition. Portugal, 1999. European Observatory on Health Care Systems. http://www. euro.who.int/observatory. 2007.

42. Norman GR, Streiner DL. Biostatistics. The bare essentials. Mosby, St. Louis, 1994.

43. Cohen BH. Explaining psychological statistics. John Wiley \& Sons, Inc. New York, 2001.

44. Martin Martins J, do Vale S. Perfil dos doentes com Diabetes Mellitus tipo 2 assistidos numa consulta hospitalar de Endocrinologia. Exploracao estatistica de parametros relevantes. Endocrinol Metab Nutr. 2002;11:1-16.

45. Martin Martins J, Afonso A, Falcao J, Charneco da Costa J. Perfil clinico, metabolico e endocrinologico do excesso de peso e obesidade. Endocrinol Metab Nutr. 1993;2:279-287.

46. Chaudhry ZW, Gannon MC, Nuttall FQ. Stability of body weight in type 2 diabetes. Diabetes Care. 2006;29(3):493-497.

47. Davies M, Brophy S, Williams R, Taylor A. The prevalence, severity, and impact of painful diabetic peripheral neuropathy in type 2 diabetes. Diabetes Care. 2006;29(7):1518-1522.

48. do Vale S, Martin Martins J. Dislipidemias em doencas endocrinas comuns-frequencia, tipos, factores antropometricos e endocrinos. Endocrinol Metab Nutr. 2003;12:149-164.

49. Soinio M, Marniemi J, Laakso M, Lehto S, Ronnemaa T. High-sensitivity C-reactive protein and coronary heart disease mortality in patients with type 2 diabetes: a 7-year follow-up study. Diabetes Care. 2006;29(2):329333.

50. Pearson TA, Mensah GA, Alexander RW, Anderson JL, Cannon RO, 3rd, Criqui M, Fadl YY, et al. Markers of inflammation and cardiovascular disease: application to clinical and public health practice: A statement for healthcare professionals from the Centers for Disease Control and Prevention and the American Heart Association. Circulation. 2003;107(3):499-511.
51. Rutter MK, Meigs JB, Sullivan LM, D'Agostino RB, Sr., Wilson PW. C-reactive protein, the metabolic syndrome, and prediction of cardiovascular events in the Framingham Offspring Study. Circulation. 2004;110(4):380-385.

52. Davignon J, Ganz P. Role of endothelial dysfunction in atherosclerosis. Circulation. 2004;109(23 Suppl 1):III27-32.

53. Arauz-Pacheco C, Parrott MA, Raskin P. The treatment of hypertension in adult patients with diabetes. Diabetes Care. 2002;25(1):134-147.

54. Haffner SM. Management of dyslipidemia in adults with diabetes. Diabetes Care. 1998;21(1):160-178.

55. Colwell JA, American Diabetes A. Aspirin therapy in diabetes. Diabetes Care. 2004;27(Suppl 1):S72-73.

56. Kovatchev BP, Otto E, Cox D, Gonder-Frederick L, Clarke W. Evaluation of a new measure of blood glucose variability in diabetes. Diabetes Care. 2006;29(11):24332438.

57. Mortensen HB, Hougaard P. Comparison of metabolic control in a cross-sectional study of 2,873 children and adolescents with IDDM from 18 countries. The Hvidore Study Group on Childhood Diabetes. Diabetes Care. 1997;20(5):714-720.

58. Eeg-Olofsson K, Cederholm J, Nilsson PM, Gudbjornsdottir S, Eliasson B, Steering Committee of the Swedish National Diabetes R. Glycemic and risk factor control in type 1 diabetes: results from 13,612 patients in a national diabetes register. Diabetes Care. 2007;30(3):496-502.

59. Saaddine JB, Engelgau MM, Beckles GL, Gregg EW, Thompson TJ, Narayan KM. A diabetes report card for the United States: quality of care in the 1990s. Ann Intern Med. 2002;136(8):565-574.

60. Resnick HE, Foster GL, Bardsley J, Ratner RE. Achievement of American Diabetes Association clinical practice recommendations among U.S. adults with diabetes, 1999-2002: the National Health and Nutrition Examination Survey. Diabetes Care. 2006;29(3):531-537.

61. Kemp TM, Barr EL, Zimmet PZ, Cameron AJ, Welborn TA, Colagiuri S, Phillips P, et al. Glucose, lipid, and blood pressure control in Australian adults with type 2 diabetes: the 1999-2000 AusDiab. Diabetes Care. 2005;28(6):1490-1492.

62. Piatt GA, Orchard TJ, Emerson S, Simmons D, Songer TJ, Brooks MM, Korytkowski M, et al. Translating the chronic care model into the community: results from a randomized controlled trial of a multifaceted diabetes care intervention. Diabetes Care. 2006;29(4):811-817. 